\title{
ON THE EFFECT OF PROSPERITY AND ADVERSITY IN THE CAUSATION OF INSANITY.
}

LETTER FROM D. YELLOWLEES, M.D., Physician-Superintendent of the Glasgow Royal Asylum.

To the Editors of the Journal of Mental Science.

Gentramen, -The above is the title of Dr. Chapman's paper in the last number of this Journal, but the question which it discusses is a much narrower one, viz., whether the production of insanity in the wage-earning popalation is greater when wages are high or when they are low.

The number and character of the admissions, and the proportion of recoveries, vary so greatly in every asylum from year to year according to many varying circumstances, and even when no difference in circumstances can bo detected, that Dr. Chapman's figures cannot be said to prove his conclusion. The doubt is strengthened when we find that althongh agricultural depression has been at least as great in 1881 as in 1880 , only nine of his selected nineteen asylums show any increase of recoveries in 1881 over those of the previous year, notwithstanding the natural increase of population.

But whaterer weight may be attached to Dr. Chapman's figures as anpporting his opinion, the opinion is assuredly correct. When the weekly wage of the agricultural labourer falls to twelve shillings and remains at that rate, no one will be disposed to doubt that his condition is one of real porerty, that diseases of debility must therefore abound, and that insanity, the result alike of physical and mental depression, must abound also.

The variations in the number of admissions to the Glamorgan Asylum, to which Dr. Chapman refers, took place under totally different circumstances. They occurred for very limited periods, amid a population of cosl and iron workers, at a time when 42 shillings weekly was deemed a low wage, and when reckless dissipation and extravagance abounded.

The following extract from a paper read in the Psychological Section of the British Medical Association at its annual meeting in 1873 gives these variations, and also my interpretation of them, which, it will be seen, is very different from the sweeping hypothesis which Dr. Chapman ascribes to me :-

"In the second half of the year 1871, the Glamorgan Connty Asylum received only 24 male patients, whereas 47 and 43 were received in the preceding and succoeding half-years. Again, in the first quarter of the year 1873 , the same asylum received only 10 male patients, whereas 21 and 18 were received in the preceding and succeeding quarters. While there was thas on two occasions, for periods of six and three months respectively, a sudden fall in the male admissions to half their usual number, the female admissions showed scarcely any disturbance.

"During the same periods a like experience was made at the County Prisons, the production of crime as well as of insanity being strikingly diminished.

"These two exceptional periods correspond exactly with the last two 'strikes' in the coal and iron trades, in which Glamorganshire is extensively engaged ; and these results only afford another proof that ignorance and selfindulgence can make prosperity a curse instead of a blessing.

"The decreased production of insanity during a strike seems mainly due to two canses- the one physical, the other moral. There is no money to spend in drinking, and there is no time to think of anything but the strike. This moral canse is more potent than might at first appear. The strike excites universal interest, and in the districts chiefly affected there is continual dis cussion of its varying prospects, its certain advantages, and its probable termination. The subject bas the deepest personal interest for all, and so en. grosses attention, that it gives stability and force to weak and wavering 
minds, just as a demented patient becomes reasonable and intelligent for a time when his attention is aroused and his scattered faculties concentrated by an illness or an accident. But the enforced abstinence from drinking and debanchery is beyond doubt the ohief canse of the decreased insanity; and this is strongly confirmed by the fact that the diminution is observed only among the men, a large proportion of whom are habitually dissipated."

These observations are in no way inconsistent with the opinion that a pro. longed strike or prolonged depression of trade and greatly diminished wages would increase the production of insanity. In such increase, both serees would saffer, and melancholia would be the prevalent type.

This is precisely what Dr. Pringle, my successor at the Glamorgan Asylum, observed in 1875, and has recorded in his annual report for that year. Commenting on the large increase of the asylum population during the year, in both sexes, but especially men, he says : "It would thus appear that a prolonged depression of trade such as the past year has witnessed has the opposite effect of a temporary 'strike.' The latter diminishes the male admissions by arresting intemperance, and its voluntary and simultaneous character braces the men to endurance; but the former, whether resulting from a 'lookout' or otherwise, is involuntary, inevitable, and prolonged, so that while equally arresting intemperance it induces a feeling of universal gloom and depression in addition to the poverty. To these influences the hardest livers are of course the first to saccumb, and thus the male admissions are materially increased."

"Amongst the admissions the unusual number of melancholiacs has been very striking, and has no doubt been caused by the depressed state of trade and the general condition of gloom and suffering thereby produced."

$\Delta$ gain, in his Annual Report for 1878 Dr. Pringle writes :-

“The admissions have been unusually numerous. . . . That such a great increase of insanity should take place at the present time, when trade is so depressed and wages so small, and the classes from which this asylum is supplied can scarcely get food and certainly have very little money to apend on drink, may well cause astonishment; but I believe this increase is simply a marked illustration of the well-known doctrine of the 'survival of the fittest' by the succumbing of those whose brains are unable to bear the strain of porerty and hardship in addition to the weakening influences of former intemperance, of family tendenoy, or other causes which might not of them. selves have induced an attack of insanity."

Whether the production of insanity in a wage-earning population is greater when wages are high or when they are low thus seems to depend mainly on circumstances, specially on the wisdom with which high wages are used, and on the length of time during which poverty has to be endured.

The experience of Glamorgan corrects while it confirms that of Hereford. Yours, \&c.,

Gartnavel,

D. YELLOWLEES.

Sept. 7, 1882.

\section{Appointments.}

BirT, C., M.R.C.S., appointed third Assistant Medical Officer to the South Yorkshire County Lunatic Asylum, vice H. C. MacBryan, L.R.C.P., rosigned.

Caxpbert, Patricr Ed., M.B., C.M., appointed Senior Assistant Medical Officer to the Metropolitan District Asylum, Caterham, Surroy, vice G. B. Secoombe, resigned.

XXVIII. 